\section{INVESTIGATION OF GROUNDWATER POTENTIALS IN IMAKUN OMI COMMUNITY USING} ELECTRICAL RESISTIVITY METHOD

${ }^{* 1}$ Coker, Joseph Olakunle; ${ }^{2}$ Agbelemoge, Akindamola Julius; ${ }^{3}$ Ariyo, Stephen Oluwafemi; ${ }^{4}$ Makinde, Victor; ${ }^{5}$ Alabi, Aderemi Amidu. and ${ }^{6} \mathrm{Emida}$, Adesina Adesola

${ }_{1,2,6}$ Department of Physics, Olabisi Onabanjo University, Ago-Iwoye

${ }^{3}$ Department of Earth Sciences, Olabisi Onabanjo University,Ago-Iwoye Ogun state, Nigeria.

${ }^{4,5}$ Department of Physics, Federal University of Agriculture, Abeokuta, Ogun State, Nigeria

Corresponding Author E-mail: coker.joseph@oouagoiwoye.edu.ng

\section{ABSTRACT}

Groundwater is described as the water found beneath the surface of the earth in underground stream and aquifers and has become popular as a source of drinking potable water in Nigeria due to its quality when compared to other water sources. The Electrical resistivity method was employed in Imakun Omi Community, a coastal town in Ogun Waterside Local government area of Ogun State with the aim of determining the groundwater potential of the area. A total of twenty (20) Vertical Electrical Soundings (VES) points were carried out in the area using the Schlumberger configuration with results obtained were interpreted quantitatively and qualitatively using partial curve matching and computer iteration programs WINRESIST and SURFER 11 for the interpretation from which the
com reflection coefficient was computed. The groundwater potential of the rock units were evaluated and $40 \%$ of the stations show high yield, $50 \%$ of the stations show medium yield and $10 \%$ of the station was observed to have low yield. The aquifer thicknesses are very thick with values ranging from $6.9 \mathrm{~m}$ to $79.3 \mathrm{~m}$, hence an average of $43.1 \mathrm{mand}$ overburden thicknesses ranging from $9.7 \mathrm{~m}$ to $96.5 \mathrm{~m}$, with an average of $53.1 \mathrm{~m}$

Keywords: Groundwater, Reflection coefficient, Terrameter, Vertical Electrical Sounding.

Accepted Date: 15 March 2018

\section{INTRODUCTION}

Many people in rural communities in Nigeria are battling with the problem of inadequate availability of potable water for their daily activities. In Imakun Omi, many of the villagers depend on streams and hand dug wells for daily water supply. Groundwater is described as the water found of the earth in underground streams and aquifers (Anomohanran, 2011). Olorunfemi et al., (1999) puts its volume at 2000 times that of the volume of water in all the world's rivers at any given time. Hence, groundwater development constitutes a viable option or supplement to the expensive concrete dam system of surface water supply, where potential groundwater is good. Various researchers have employed different methods in exploring this very essential life sustaining resource. Geophysical

urveys have been most widely used because of the basic advantage of providing more accurate results resistivity survey method is the detection of the current inside the earth (Afuwai, 2014). T determine the depth to freshwater aquifer in the study area.

Location and Geology of the study area

Imakun Omi is situated in Ogun Waterside Local Government Area in the Ijebu Division of Ogun State. A tropical rain forest region in the Southern Sub-Saharan, located in the eastern part of Ogun state sharing boundaries with Ondo state in the north, Lagos state in the south and Ijebu East local government area in the west (figure 1). About half to three quarters of the length of the local government area is surrounded by water extending from Lagos state to Ondo state. It is close to the Atlantic Ocean and has relative endowment with a complex network of streams, rivers, brackis water. Imakun Omi is located on longitude $4^{\circ} 24^{\prime} \mathrm{E}$ and latitude $6^{\circ} 26^{\prime} \mathrm{N}$, and lies within the coasta plain which is characterised by sand bars and lagoon creeks which is almost encompassed by the Lagos lagoon system, hence the terrain is sedimentary.

\section{Materials and Methods}

For the purpose of this research, 20 Vertica Electrical Soundings were carried out in the study area using Schlumberger electrode array. The basic field equipment used for the study is the ABEM TERRAMETER SAS 1000 which display apparen resistivity value digitally as computed from Ohm's than other methods (Anomohanran, 2013). This advantage includes, simplicity in field techniques and data handling procedures. The electrical surface effects produced by the flow of electric determination of subsurface esistivity by sending an electric current into the ground and measuring the electrical potential produced by the current. The subsurface resistivity distribution is related to physical conditions such as lithology, porosity and presence of voids in the rocks. The apparent resistivity is the bulk average resistivity of all soils and rock influencing the current. The objectives of the study are to determine the lithology of the subsurface and
In the VES, the four electrodes are positioned symmetrically along a straight line, the curren electrodes on the outside and the potentia electrodes on the inside. Measurements of current and potential electrode positions are marked such that $\mathrm{AB} / 2 \geq \mathrm{MN} / 2$.

where $\mathrm{AB} / 2=$ Current electrode spacing and

$\mathrm{MN} / 2=$ Potential electrode spacing

The results of the measurements are recorded in the $\log -\log$ sheet and later inputted into the compute for interpretations. Processing of the field data was done using the partial curve matching for manua interpretation and then the computer iterated technique. The subsurface models were then generated from the geo-electric parameters by computer aided iteration softwares; WINRESIST
1.0 and SURFER 11. The models obtained from the provided data such as the resistivity's and overburden thickness which were used to plot the isopach map, isoresistivity map and reflection coefficient map.

Results and Discussions

The results are presented in form of field curves (figure 2) which was used to infer the lithology of the study area. The result reveal perfect matched curves, layered parameters and RMS error and it the various numbers of layers, their resistivity values with varying depth and thickness.

The number of layers inferred from the twenty $(20)$ VES points range from four (4) to five (5) and are described as topsoil, lateritic sand, alluvium, clay, shale, clay, sandy clay, clayey sand, saline clay, sandstone, coarse sand and freshwater sand based on the values of their corresponding resistivities. The summary of the subsurface obtained from the computer interpretation is presented in table 1.

Table 2 shows the occurrence of the curves types in a frequency, percentage and degrees and this was used to design a Pie-chart depicting the occurrence of the curves type in figure 4. In Imakun Omi, as shown in Figure 4, KQ curve type is most predominant $40 \%$, followed by KQQ with $20 \%$ and $\mathrm{KQH}$ with $15 \%$ while $\mathrm{KHA}, \mathrm{KH}, \mathrm{AKQ}, \mathrm{QH}$ and HK are the least predominant each having 5\% occurrence in the study area.

The topsoil has resistivity values ranging from $1131.6 \Omega \mathrm{m}$ to $7721.7 \Omega \mathrm{m}$, having an average resistivity value of $4426.6 \Omega \mathrm{m}$. The thickness value corresponding to the topsoil range from $0.3 \mathrm{~m}$ to 3.9 and having an average layer thickness of $2.1 \mathrm{~m}$. The resistivity of the weathered layer ranges from 130.9 $\Omega \mathrm{m}$ to $5180.2 \Omega \mathrm{m}$ with an average $2655.5 \Omega \mathrm{m}$ and aquifer thickness ranging from $6.9 \mathrm{~m}$ to $79.3 \mathrm{~m}$, hence an average of $43.1 \mathrm{~m}$. The basemen resistivity ranges from $106.6 \Omega \mathrm{m}$ to $487.9 \Omega \mathrm{m}$, and average of $297.2 \Omega \mathrm{m}$ for the fractured basemen while fresh basement range from $1653.5 \Omega \mathrm{m}$ to $31801.1 \Omega \mathrm{m}$ an average of $16727.3 \Omega \mathrm{m}$ while the depth to bedrock range from $9.7 \mathrm{~m}$ to $96.5 \mathrm{~m}$ with an average of $52.2 \mathrm{~m}$ while the overburden thickness ranges from $9.7 \mathrm{~m}$ to $96.5 \mathrm{~m}$, with an average of 
$53.1 \mathrm{~m}$.

Isopach Map

Isopach Map is a map illustrating thickness variation within a layer, tabular unit or stratum. The overburden thickness is the sum total of the thickness of the layers that is above the bedrock in a given location. It is also important in hydrogeological investigation as it shows the distances of layers that is above the aquifer and groundwater has been observed to be present in areas which have a considerable overburden thickness (Coker et al., 2013). The Isopach maps for Overburden thickness as depicted in figure 4 shows Imakun Omi has high thickness at the central and towards the south yet lowest at the southwest and averagely high at the northeast.

The Aquifer thickness is the thickness of the layer that bears sufficient amount of groundwater in a given location. It is however expected that the groundwater yield is proportional to the thickness of the aquiferous layer. Hence, the higher the thickness of the aquifer, the more its capacity to bear groundwater. Imakun Omi has very high aquifer thickness at the central and lowest at the southwest and northwest ends and rising slightly towards the east and the southeast as shown in figure 5 .

\section{Isoresistivity map}

The bedrock resistivity is the resistivity of the last layer within the study area. The resistivity of the bedrock has been found useful in many aspects of geology and hydrogeophysical surveys as it plays a vital role in the evaluation of groundwater because the resistivity of bedrock has the ability to reveal if there is fracture in some bedrock and this has been considered to be the major host of groundwater in some areas. Imakun Omi too has generally low but very high at the southeastern edge as depicted in figure 6 . The we athered resistivity map records very high at the southeast $\mathrm{r}$

\section{Reflection Co-Efficient}

The reflection coefficients ( $\mathrm{r}$ ) of the study area were calculated using the method of Loke (1999), equations 1 and 2 . The reflection coefficient is an important parameter because it helps to indicate fractured areas that host groundwater i.e areas with reflection coefficient values $<0.8$

Reflection Coefficient (R.F) $=$

Resistivity of (Last Layer - Second to the Last Layer)

$\mathrm{r}=\frac{(\rho n-\rho(n-1))}{(\rho n+\rho(n-1))}$

where $\rho_{n}$ is the layer resistivity of the nth layer

$\rho_{(n-1)}$ is the layer resistivity overlying the nth layer.

The Reflection Coefficient have been found useful in hydrogeological aquifer investigation because it reveals if bedrock fracture is filled with water and here must be a direct correlation with the nisotropy coefficient value for this parameter to be considered. The nature of the basement is not dependent on the absolute resistivity values but rather dependent on its reflection coefficient values, which measures the competency of the rock (Olayinka, 1996). Areas with relatively lower reflection coefficient represent areas where the bedrock is either fractured or weathered Such areas have higher groundwater potential than areas with higher values of reflection coefficient $(>0.8)$ i.e
fresh basement. The Reflection Coefficient value fresh basement. The Reflection Coefficient value
within the study area ranges from 0.05 to 2.1 hence, within the study area ranges from 0.05 to 2.1 hence,
an average of 1.1. As shown in figure 8 , it is highest at the West and at the North

\section{Groundwater potential evaluation}

Olayinka (1996) observed that the resistivity of the basement cannot be solely relied on to identify areas of promising aquifers. Hence, the consideration of its reflection coefficient brought a better result. It shows the degree of fracturing of the underlying basement better, than depending solely on the resistivity values. Good aquiferous zones are usually found either where the overburden is relatively thick and or where the reflection coefficient is low $(<0.8)$. Three basic criteria were considered in evaluating promising points for groundwater potential (i.e areas with high yield, medium yield and low yield) which are:

I. Areas with overburden thickness greater than $13 \mathrm{~m}$ (even if their resistivity is relatively high).

ii. Areas with reflection coefficient less than 0.8

iii. Areas with resistivity less than $2000 \Omega \mathrm{m}$.

In order to ensure maximum and perennial yield, boreholes are best sited in areas where the regoliths could be maximally penetrated. As shown by Olayinka (1996), this was used to produce the parameters for categorizing the groundwate potential yield into: high, medium and low. VES's $3,4,9,15,16,17,19$ and 20 show high yield which makes $40 \%$ of the stations in the town. Medium

yield is observed at 1, 2, 6, 7, 8, 10,12,13,14 and 18 making $50 \%$ of the stations. Low yield is observed at VES's 5 and 11 making $10 \%$ of the stations in the town as shown in table 3 .

Table 1: Geocl octric Parameters

\begin{tabular}{|c|c|c|c|c|c|c|}
\hline VES NO & NO OF LAYERS & CURVE TYPE & $\begin{array}{l}\text { RESISTIVITY } \\
(? \mathrm{~m})\end{array}$ & $\begin{array}{l}\text { THICKNESS } \\
(\mathrm{m})\end{array}$ & $\begin{array}{l}\text { DEPTH } \\
(\mathrm{m})\end{array}$ & LITHOLOGY \\
\hline \multirow[t]{5}{*}{1} & 5 & $\mathrm{KOH}$ & 1217.6 & 0.4 & 0.4 & Topsoil \\
\hline & & & 8324.3 & 1.3 & 1.8 & Laterittic Sand \\
\hline & & & 1006.2 & 9.9 & 11.6 & Shale \\
\hline & & & 130.9 & 79.3 & 91.0 & Sandy clay \\
\hline & & & 5381.4 & -- & -- & Fresh Basement \\
\hline \multirow[t]{4}{*}{2} & 4 & KQ & 3469.2 & 0.4 & 0.4 & Topsoil \\
\hline & & & 73686.7 & 1.7 & 2.1 & Laterittic Sand \\
\hline & & & 1328.9 & 27.0 & 29.1 & Shale \\
\hline & & & 106.6 & -- & --- & Sandy clav \\
\hline \multirow[t]{4}{*}{3} & 4 & $K Q$ & 4637.5 & 0.5 & 0.5 & Topsoil Laterittic \\
\hline & & & 26230.2 & 4.1 & 4.6 & Sand \\
\hline & & & 2003.7 & 25.5 & 30.2 & Shale \\
\hline & & & 452.9 & -- & --- & Alluvium \\
\hline \multirow[t]{5}{*}{4} & 5 & $K Q Q$ & 7721.7 & 0.3 & 0.3 & Topsoil \\
\hline & & & 40815.8 & 2.2 & 2.5 & Laterittic Sand \\
\hline & & & 3623.4 & 14.6 & 17.1 & Shale \\
\hline & & & 481.9 & 49.1 & 66.2 & Alluvium \\
\hline & & & 164.6 & -- & -- & Sandy clay \\
\hline \multirow[t]{4}{*}{5} & 4 & KQ & 1524.4 & 0.4 & 0.4 & Topsoil \\
\hline & & & 27378.0 & 1.4 & 1.8 & Laterittic Sand \\
\hline & & & 823.4 & 10.2 & 12.0 & Shale \\
\hline & & & 364.1 & -- & -- & Alluvium \\
\hline \multirow[t]{4}{*}{6} & 4 & KQ & 1498.0 & 0.5 & 0.5 & Topsoil \\
\hline & & & 20092.8 & 2.3 & 2.8 & Laterittic Sand \\
\hline & & & 1068.1 & 12.5 & 15.3 & Shale \\
\hline & & & 373.0 & -- & -- & Alluvium \\
\hline \multirow{5}{*}{7} & 5 & $\mathrm{KOH}$ & 1185.3 & 0.4 & 0.4 & Topsoil \\
\hline & & & 21592.7 & 1.6 & 2.0 & Laterittic Sand \\
\hline & & & 965.3 & 2.3 & 4.3 & Shale \\
\hline & & & 315.9 & 73.1 & 77.4 & Alluvium \\
\hline & & & 2612.7 & --- & --- & Fresh Basement \\
\hline \multirow[t]{4}{*}{8} & 4 & $\mathrm{QH}$ & 2191.8 & 3.7 & 3.7 & Topsoil \\
\hline & & & 982.7 & 8.4 & 12.1 & Sandstone \\
\hline & & & 248.8 & 22.2 & 34.3 & Alluvium \\
\hline & & & 2379.2 & -- & --- & Fresh Basement \\
\hline \multirow[t]{5}{*}{9} & 5 & KHA & 1853.4 & 1.1 & 1.1 & Topsoil \\
\hline & & & 2502.7 & 4.1 & 5.2 & Laterittic Sand \\
\hline & & & 445.9 & 12.0 & 17.1 & Alluvium \\
\hline & & & 5180.2 & 22.9 & 40.0 & Dry Sand \\
\hline & & & 31801.1 & --- & --- & Fresh Basement \\
\hline \multirow[t]{4}{*}{10} & 4 & $\mathrm{KH}$ & 1833.0 & 2.8 & 2.8 & Topsoil \\
\hline & & & 2427.5 & 3.7 & 6.6 & Laterittic Sand \\
\hline & & & 320.7 & 12.6 & 19.1 & Alluvium \\
\hline & & & 4945.7 & --- & -- & Fresh Basement \\
\hline
\end{tabular}




\begin{tabular}{|c|c|c|c|c|c|c|}
\hline \multirow[t]{4}{*}{11} & 4 & $\mathrm{KQ}$ & 1457.1 & 0.6 & 0.6 & Topsoil \\
\hline & & & 7042.6 & 2.2 & 2.8 & Laterittic Sand \\
\hline & & & 1259.6 & 6.9 & 9.7 & Shale \\
\hline & & & 141.7 & -- & - & Sandy clay \\
\hline \multirow{4}{*}{12} & 4 & $\mathrm{KQ}$ & 1390.6 & 0.7 & 0.7 & Topsoil \\
\hline & & & 4819.6 & 3.4 & 4.0 & Laterittic Sand \\
\hline & & & 607.3 & 16.1 & 20.1 & Alluvium \\
\hline & & & 148.1 & - & - & Clayey sand \\
\hline \multirow[t]{4}{*}{13} & 4 & $\mathrm{KQ}$ & 1506.8 & 0.7 & 0.7 & Topsoil \\
\hline & & & 4207.1 & 3.7 & 4.4 & Alluvium \\
\hline & & & 593.5 & 13.6 & 18.0 & Shale \\
\hline & & & 124.8 & -- & - & Sandy clay \\
\hline \multirow[t]{5}{*}{14} & 5 & $\mathrm{KQH}$ & 1161.3 & 0.7 & 0.7 & Topsoil \\
\hline & & & 4397.4 & 2.8 & 3.5 & Laterittic Sand \\
\hline & & & 755.9 & 15.0 & 18.5 & Alluvium \\
\hline & & & 174.0 & 78.0 & 96.5 & Sandy Clay \\
\hline & & & 1653.5 & - & -- & Fresh Basement \\
\hline \multirow[t]{4}{*}{15} & 4 & HK & 1131.6 & 3.9 & 3.9 & Topsoil \\
\hline & & & 220.0 & 3.5 & 7.4 & Alluvium \\
\hline & & & 1958.1 & 25.5 & 32.9 & Dry Sand \\
\hline & & & 312.8 & - & - & Clay \\
\hline \multirow[t]{4}{*}{16} & 4 & $\mathrm{KQ}$ & 2133.1 & 0.5 & 0.5 & Topsoil \\
\hline & & & 18088.2 & 1.8 & 2.3 & Laterittic Sand \\
\hline & & & 1720.3 & 24.8 & 27.1 & Dry Sand \\
\hline & & & 263.4 & -- & --- & Alluvium \\
\hline \multirow[t]{5}{*}{17} & 5 & KQQ & 2151.3 & 0.5 & 0.5 & Topsoil \\
\hline & & & 13696.2 & 1.7 & 2.2 & Laterittic Sand \\
\hline & & & 3930.9 & 12.1 & 14.4 & Shale \\
\hline & & & 1258.6 & 38.5 & 52.8 & Dry Sand \\
\hline & & & 211.4 & -- & -- & Alluvium \\
\hline \multirow[t]{5}{*}{18} & 5 & KQQ & 1439.8 & 0.5 & 0.5 & Topsoil \\
\hline & & & 16674.2 & 2.0 & 2.5 & Laterittic Sand \\
\hline & & & 3977.7 & 8.1 & 10.6 & Shale \\
\hline & & & 1296.7 & 36.0 & 46.6 & Dry Sand \\
\hline & & & 226.5 & -- & -- & Alluvium \\
\hline \multirow[t]{4}{*}{19} & 4 & $\mathrm{KQ}$ & 2078.7 & 0.6 & 0.6 & Topsoil \\
\hline & & & 11190.9 & 3.1 & 3.7 & Laterittic Sand \\
\hline & & & 2394.0 & 21.8 & 25.4 & Shale \\
\hline & & & 487.9 & -- & -- & Alluvium \\
\hline \multirow[t]{5}{*}{20} & 5 & AKQ & 1717.2 & 0.7 & 0.7 & Topsoil \\
\hline & & & 2561.9 & 11.2 & 11.9 & Laterittic Sand \\
\hline & & & 2913.0 & 15.7 & 27.6 & Shale \\
\hline & & & 1579.5 & 22.5 & 50.1 & Dry Sand \\
\hline & & & 481.3 & - & --- & Alluvium \\
\hline
\end{tabular}

Table 2: The occurrence of the curves type

\begin{tabular}{llll} 
Type of Curves & Frequency & Percentage & Degrees \\
\hline KQH & 3 & 15 & 54 \\
KQ & 8 & 40 & 144 \\
KQQ & 4 & 20 & 72 \\
KHA & 1 & 5 & 18 \\
KH & 1 & 5 & 18 \\
AKQ & 1 & 5 & 18 \\
QH & 1 & 5 & 18 \\
HK & 1 & 5 & 18 \\
TOT AL & 20 & 100 & 360 \\
\hline
\end{tabular}

Table 3:Aquifer Characteristics of the VES Points

Location Overburden thickness Reflection coefficient Basementresistiviy

\begin{tabular}{lllll}
\hline 1 & 91 & 0.9 & 5381.4 & MEDIUM \\
2 & 29.1 & 0.9 & 106.6 & MEDIUM \\
3 & 30.2 & 0.7 & 452.9 & HIGH \\
4 & 66.2 & 0.7 & 164.6 & HIGH \\
5 & 12 & 0.9 & 364.1 & LOW \\
6 & 15.3 & 0.9 & 373 & MEDIUM \\
7 & 77.4 & 0.9 & 2612.7 & MEDIUM \\
8 & 34.3 & 0.8 & 2379.2 & MEDIUM \\
9 & 40 & 0.7 & 31801.1 & HIGH \\
10 & 19.1 & 0.8 & 4945.7 & MEDIUM \\
11 & 9.7 & 0.8 & 141.7 & LOW \\
12 & 20.1 & 2 & 148.1 & MEDIUM \\
13 & 18 & 1.4 & 124.8 & MEDIUM \\
14 & 96.5 & 0.8 & 1653.5 & MEDIUM \\
15 & 32.9 & 0.7 & 312.8 & HIGH \\
16 & 27.1 & 0.7 & 263.4 & HIGH \\
17 & 52.8 & 0.1 & 211.4 & HIGH \\
18 & 46.6 & 2.1 & 226.5 & MEDIUM \\
19 & 25.4 & 0.6 & 487.9 & HIGH \\
20 & 50.1 & 0.6 & 481.3 & HIGH
\end{tabular}




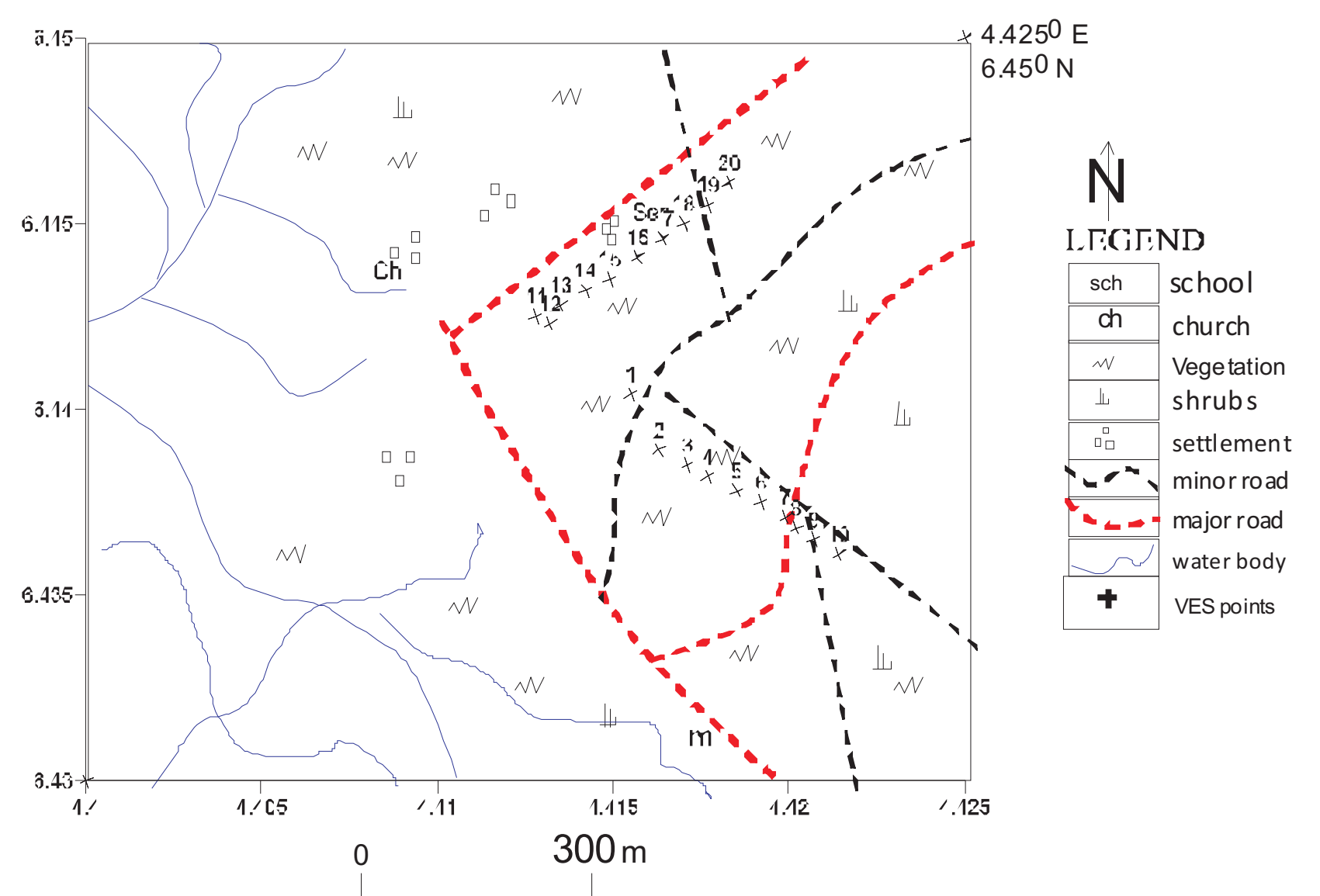

Figure 1: Location map of the study area showing the Sounding points

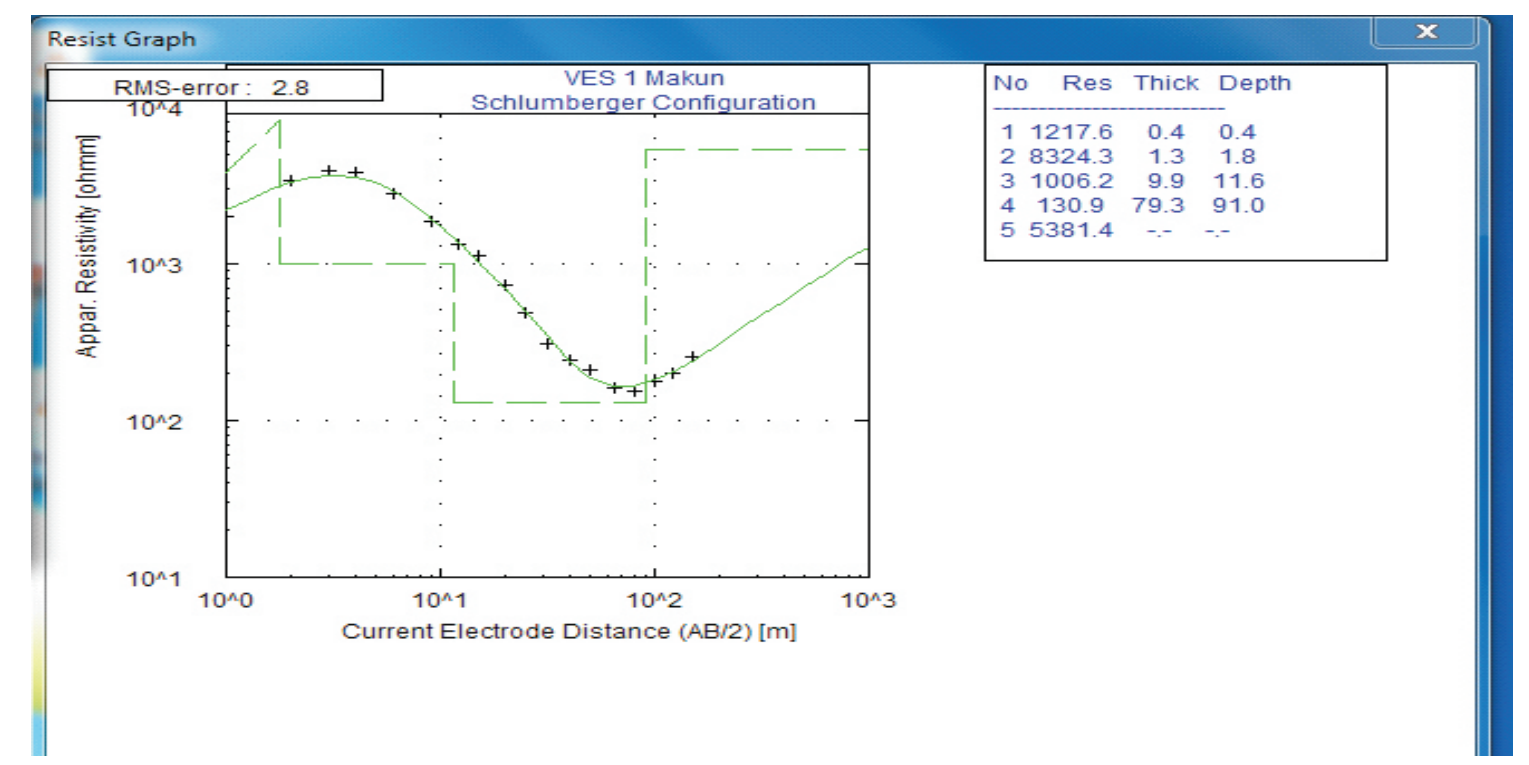

Figure 2: Typical iterated curve for VES 1

P-ISW 2536-6904 African Journal of Science \& Nature Vol. 7, 19-28 (2018)

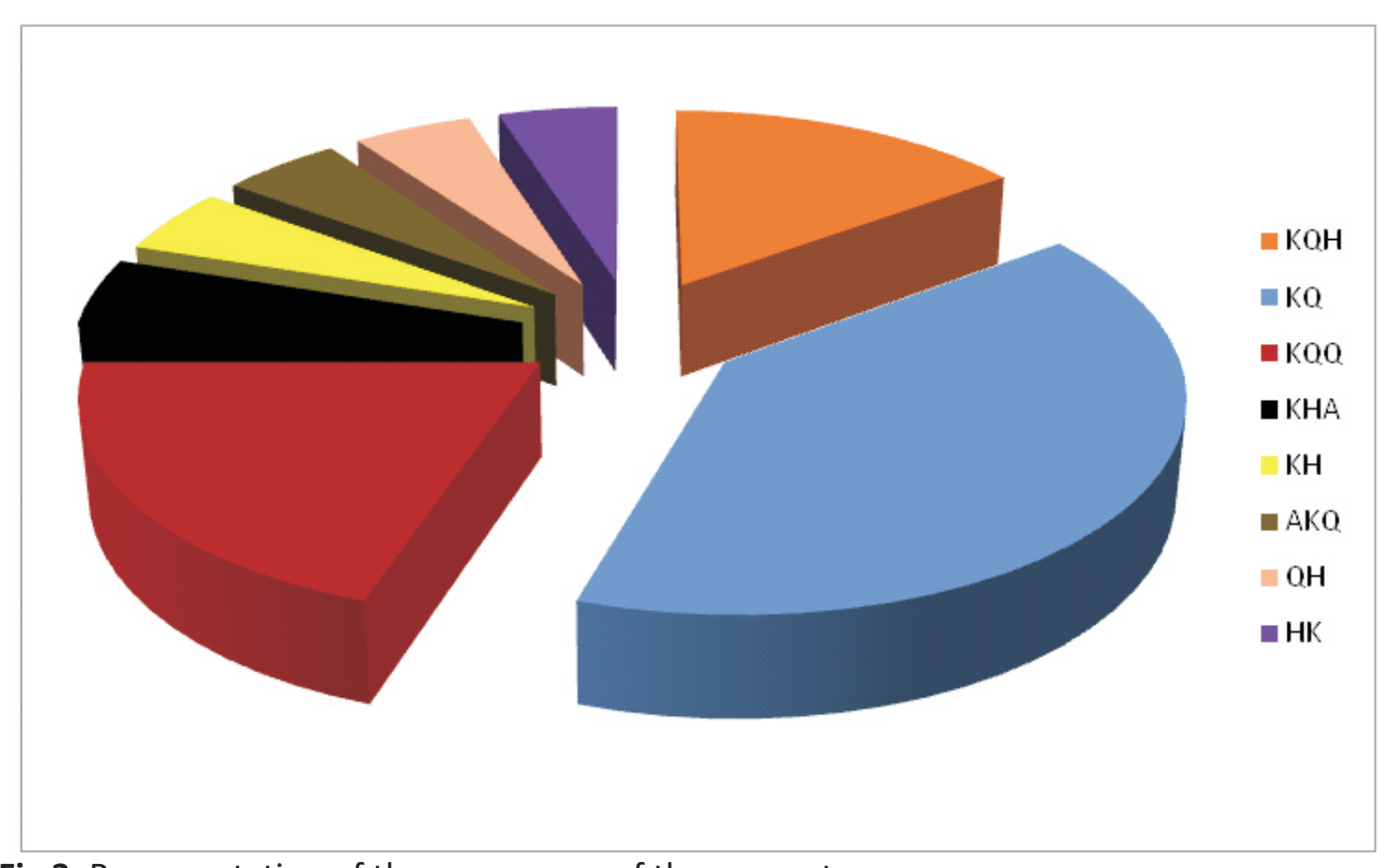

Fig 3: Representation of the occurrence of the curves type
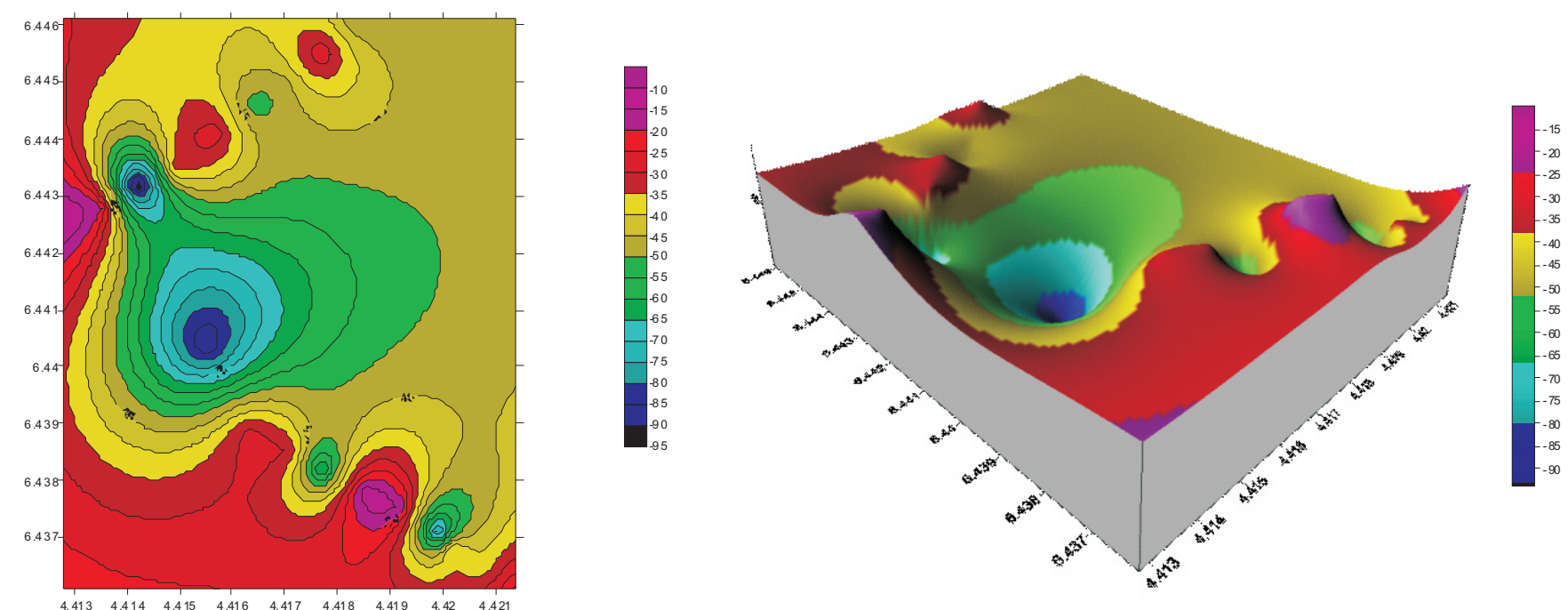

Figure 4: Maps of Overburden thickness
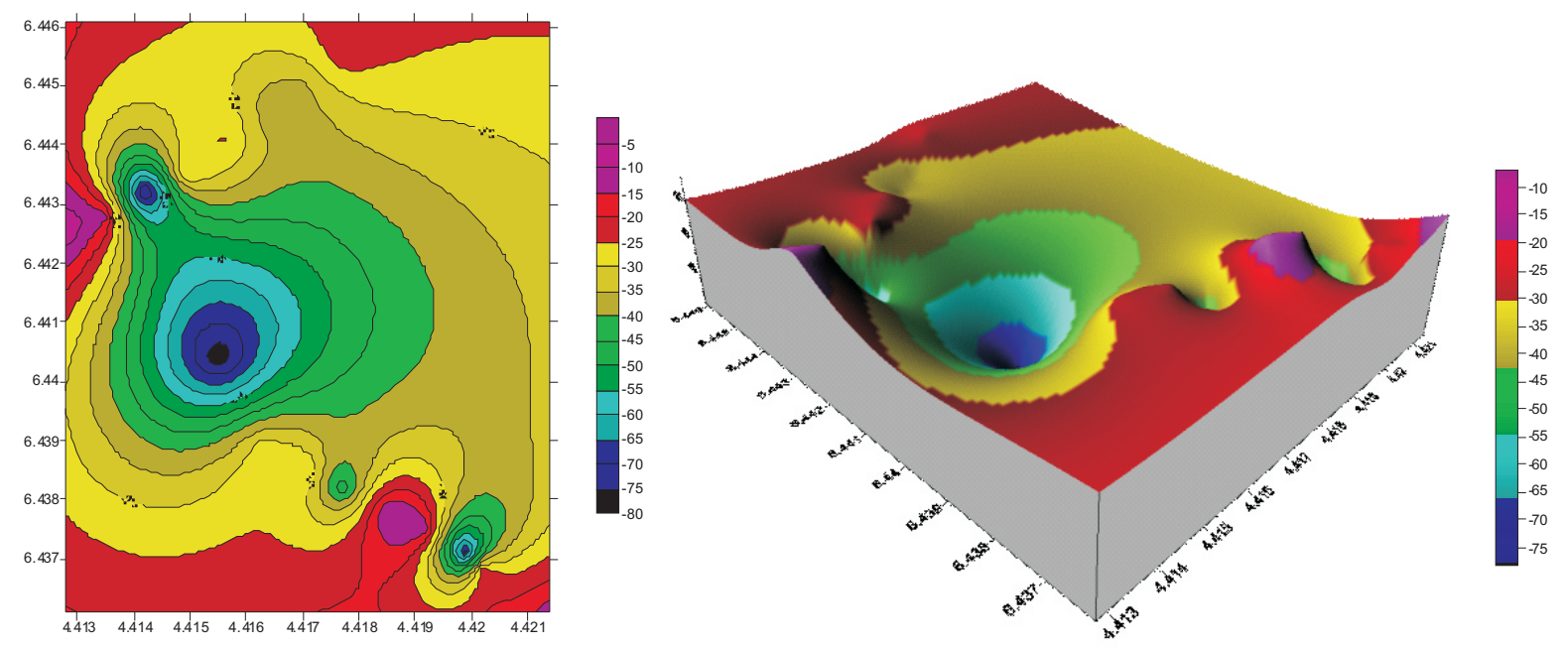

Figure 5: Maps of Aquifer thickness

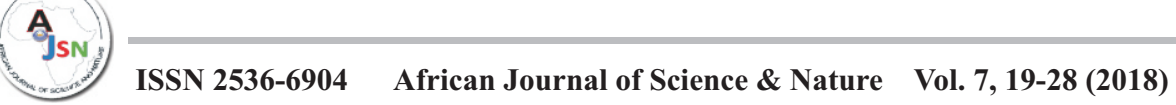



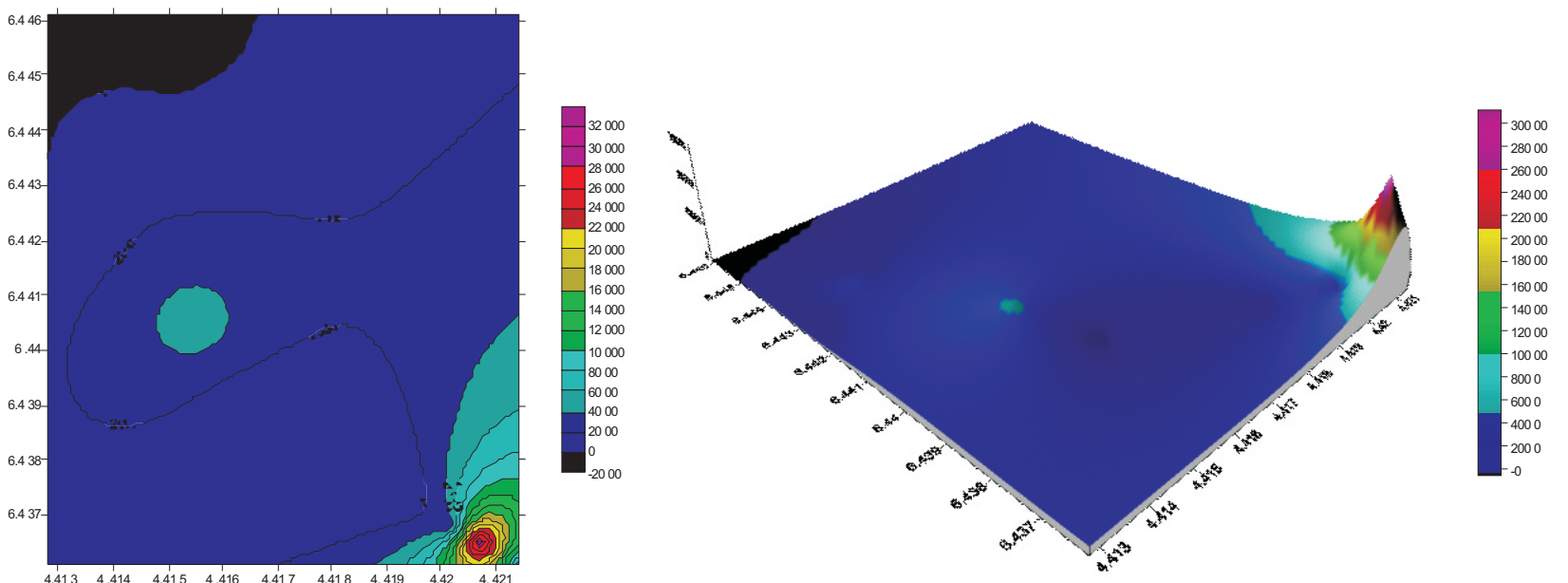

Figure 6: Isoresistivity Maps of basement layer
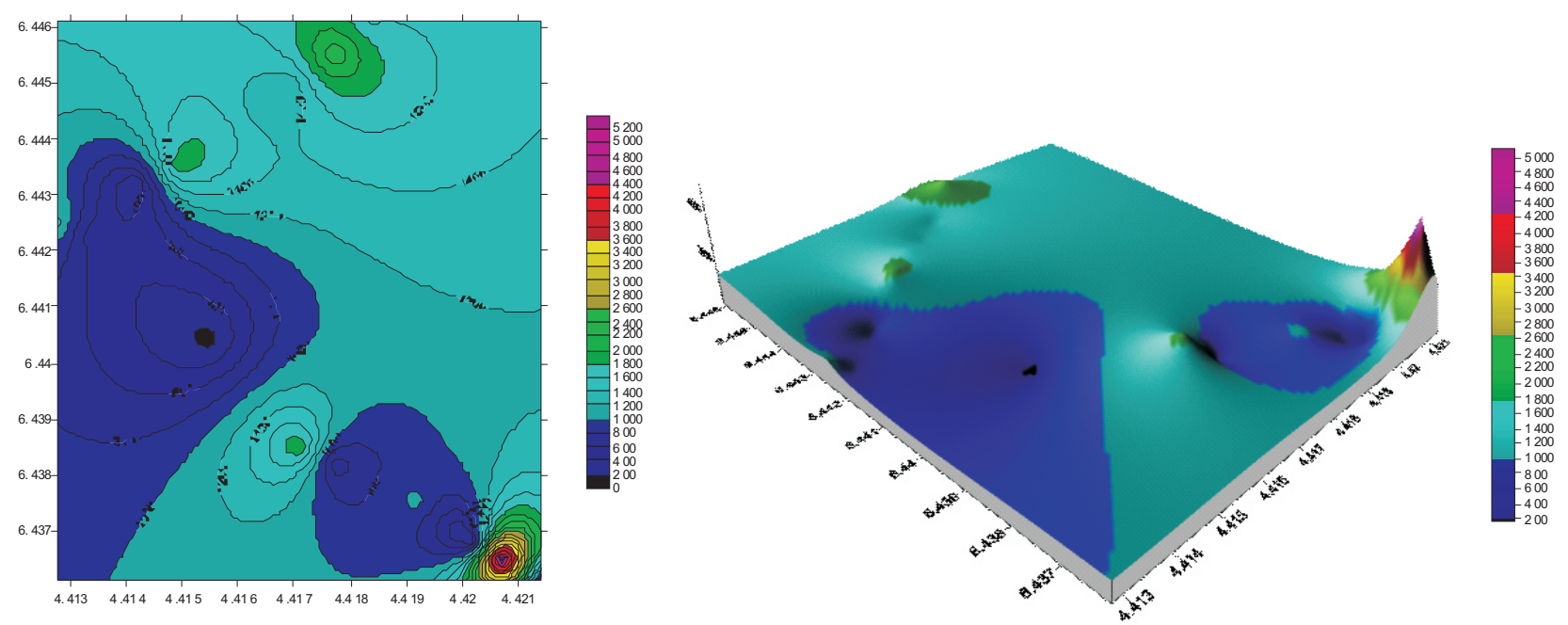

Figure 7: Isoresistivity Maps of weathered layer
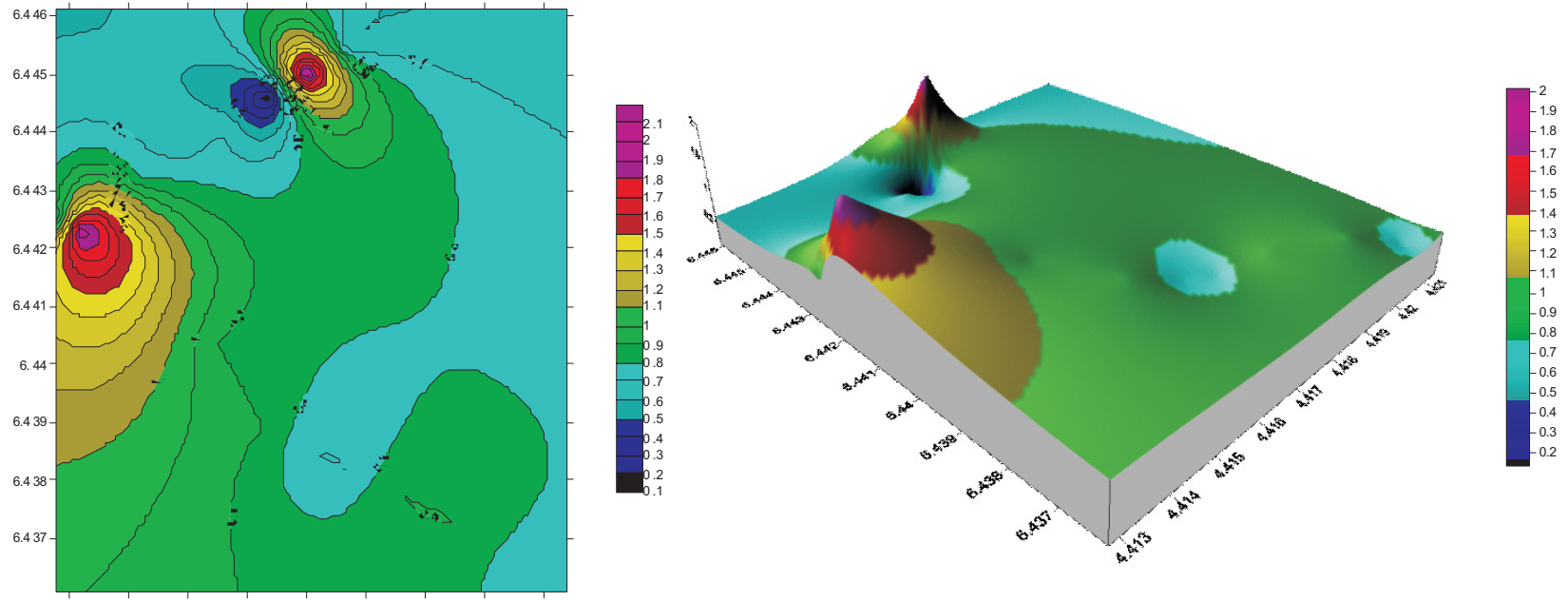

Figure 8: Reflection Coefficient maps

\section{Conclusion}

This work assessed the subsurface lithology, aquifer depth, thickness, aquifer characteristics and pollution vulnerability in Imakun Omi community. The aim is to minimize the rate of ground water exploitation failures, evaluate groundwater potential and yield and delineate areas most vulnerable to underground water pollution. The groundwater potential and protective capacity evaluation of the rock units were evaluated. $40 \%$ of the stations show high yield, $50 \%$ of the stations show medium yield and $10 \%$ of the stations was observed to have low yield. The protective capacity rating of the study area shows a mix of poor, weak and moderate ratings of the VES points. Areas that are classified as poor and weak are indicative of zones of high infiltration rates from precipitation. Such areas are vulnerable to infiltration of leachate and other surface contaminants. The groundwater in the area of weak protective capacity is buried underground storage tanks; a sore le leage of (a) environmental hazard.

The study has however been able to highlight the importance of resistivity method in effective hydrogeologic assessment of aquifers and its vulnerability to near-surface contaminants that might have pave way into the aquifers. Future groundwater development and facilities such as underground petroleum storage tanks in the study area by government should be concentrated within the medium ground water potential zones with moderate aquifer protective capacity. The results of this study have provided reliable information for an elaborate groundwater abstraction and environmental factors necessary for planning and development of residential and industrial estates in this town.

\section{References}

G. C. (2014); Geophysical Investigation of Groundwater Potential of Kongo campus ABU, Zaria, Nigeria. European Journal of Educational Studies 7(1).

Alile, M. O., Jegede, S. I. and Ehiogiator, O. M. (2008); "Underground water exploration using electrical resistivity method in Edo State

Anomohanran, O. (2011); "Determination of Groundwater Potential in Asaba, Nigeria using surface geolectric sounding", International Journal of the Physical Sciences, 6 (33): 76517656

Anomohanran, O.(2013); "Investigation of Groundwater Potential in some selected towns in Delta North District of Nigeria". International Journal of Applied Science and Technology 3(6): 61-65.
Ayolabi, E. A.; Folorunsho, A. F.; Odukoya, A. M. and Adeniran, A. E. (2013); "Mapping saline water intrusion into the coastal aquifer with geophysical and geochemical techniques: the University of Lagos campus case". Springe Publication. 2: 433

Barker, R. D. (1981); "The inversion of geoelectric geoelectric data for hydrogeological applications ne crystalline basement areas of Nigeria". $J$ O. Makinde $\mathrm{V}$., Mustapha

tapha A. O and Adesodun, J. K. (2013); "Electrical Imaging for Foundation Failure Investigation at Remo Secondary School, Sagamu Southwestern Ni . International Science Investigation Journal 12 (4): $27-33$

Golam, S. S, Keramat M, and Shahid M. (2014); "Deciphering transmissivity and hydratic conductivity of the aquifer by vertical electrical sounding (VES) experiments in Northwes Bangladesh", Appl Water Sci, 9(20):343-354

Henriet, J. P. (1976): "Direct applications of the Dar Zarrouk parameters in ground water surveys". Geophysical Prospecting, 24. 345-353.

Koefoed, O. (1979); "Geosounding Principles 1D Resistivity sounding measurements". Elsevie Science Publishing Company, Amsterdam

Lateef, T. A. (2012); "Geophysical Investigation for Groundwater using Electrical Resistivity Method-A case study of Annunciation Grammar School, Ikere LGA, Ekiti State, Southwestern Nigeria". IOSR Journal of Applied Physics 2 (1):44-47.

Lawrence, A.O. and Ojo, T. A. (2012): "The use of combined Geophysical survey methods for groundwater prospecting in a typical basement complex terrain; Case Study of Ado Ekiti Southwest Nigeria". Research Journal in Engineering and Applied Sciences 1(6): 362-376

Oborie, E. L and Udom G. J. (2014), Determination of aquifer transmissivity using geoelectrical sounding and pumping test in parts of Bayelsa State, Nigeria". Peak Journal of Physical and Environmental Science Research.14(1):549-556 Oladapo, M. I. and Akintorinwa, O. J. (2007); "Hydrogeophysical study of Ogbese Southwestern, Nigeria". Global J. Pure and App. Sci. 13(1): $55-61$.

Olayinka A. I. (1996); "Non-uniqueness in the interpretation of bedrock resistivity from sounding curves and its hydrogeologica

Olorunfemi, M. O., Ojo, J. S. and Akintunde, O. M. (1999): "Hydrogeophysical evaluation of the groundwater potential of Akure metropolis, Southwestern Nigeria". Journal of Mining and Geology.35(2) 207-0228. 